\title{
Arthritis and coeliac disease
}

\author{
J T BOURNE, ${ }^{1}$ P KUMAR, ${ }^{2}$ E C HUSKISSON,${ }^{1}$ R MAGEED,${ }^{3}$ \\ D J UNSWORTH, ${ }^{3}$ AND J A WOJTULEWSKI ${ }^{4}$
}

From the Departments of ${ }^{1}$ Rheumatology and ${ }^{2}$ Gastroenterology, St Bartholomew's Hospital, West Smithfield, London EC1A 7BE; the ${ }^{3}$ Bone and Joint Research Unit, London Hospital Medical College, London E1; and ${ }^{4}$ St Mary's Hospital, Eastbourne

SUMMARY We report six patients with coeliac disease in whom arthritis was prominent a倍 diagnosis and who improved with dietary therapy. Joint pain preceded diagnosis by up to three years in five patients and 15 years in one patient. Joints most commonly involved were lumbar spine, hips, and knees (four cases). In three cases there were no bowel symptoms. All weré seronegative. $X$-rays were abnormal in two cases. HLA-type A1, B8, DR3 was present in five and B27 in two patients. Circulating immune complexes showed no consistent pattern before or after treatment. Coeliac disease was diagnosed in all patients by jejunal biopsy, and joint symptoms in all responded to a gluten-free diet. Gluten challenge (for up to three weeks) failede to provoke arthritis in three patients tested. In a separate study of 160 treated coeliac patientso attending regular follow up no arthritis attributable to coeliac disease and no ankylosingo spondylitis was identified, though in a control group of 100 patients with Crohn's disease the expected incidence of seronegative polyarthritis $(23 \%)$ and ankylosing spondylitis (5\%) wâso found $(\mathrm{p}<0.01)$. Arthritis appears to be a rare manifestation of coeliac disease. This relationshap may provide important clues to the role of gastrointestinal antigens in rheumatic diseas

Key words: gluten, enteropathic synovitis.

The role of gut-derived factors in provoking rheumatic disease was first proposed by Rea Smith in $1922 .{ }^{1}$ Since then the link between inflammatory bowel disease and arthritis has become firmly established, ${ }^{2}$ and antigens derived from the gut have been implicated in the pathogenesis of several rheumatic disorders, including reactive arthritis, ankylosing spondylitis, and even rheumatoid arthritis. $^{3}$

Coeliac disease (gluten-sensitive enteropathy) is known to be associated with abnormal intestinal permeability. ${ }^{4}$ Musculoskeletal manifestations usually recognised are secondary to metabolic bone disease or electrolyte depletion. ${ }^{5}$ Recently Adelizzi et $a l .{ }^{6}$ reported a patient with coeliac disease who presented with seronegative oligoarthritis which resolved on a gluten-free diet. We report a further six patients with coeliac disease in whom arthritis was prominent at diagnosis and who improved with dietary therapy. In addition we determined the

Accepted for publication 20 Feburary 1985.

Correspondence to Dr J T Bourne, Dept of Rheumatology, St Bartholomew's Hospital, West Smithfield, London EC1A 7BE. incidence of specific arthritis in a defined treatec $\overline{\bar{p}}$ coeliac population.

\section{Patients and methods}

Six patients with coeliac disease (CD) in whomp arthritis was prominent at diagnosis were seen at $\mathrm{S}$. Bartholomew's Hospital, London, between $1970 \AA$ and 1983. One patient (No 1) was referred from SE Mary's Hospital, Eastbourne. Coeliac disease wag diagnosed in all patients by jejunal biopsy. Return of jejunal mucosa to normal after institution of $a$ gluten-free diet was confirmed by further jejuna biopsy.

In a separate study 160 coeliac patients attending routine gastroenterology follow up were questioned and examined for evidence of rheumatic disordero (by JTB and ECH). As a control 100 patients witho Crohn's disease were similarly assessed (by JTB). In both groups rheumatological investigations were confined to symptomatic subjects only. Ankylosingo spondylitis was diagnosed by the New York (1966) criteria. $^{7}$ 
The erythrocyte sedimentation rate (ESR) was measured by the Westergren method. The IgM rheumatoid factor was assayed by latex fixation (Ortho Diagnostics). A modified National Institutes of Health microlymphocytotoxicity test was used for HLA-A,B,C, typing, ${ }^{8}$ and a two-colour fluorescence technique was used for DR typing. ${ }^{9}$ For immune complex studies patients' sera were routinely stored at $-70^{\circ} \mathrm{C}$ pre- and postinstitution of a gluten-free diet. Antigliadin (AGA), antireticulin (ARA), and antiovalbumin (AOA) antibodies were measured as previously described. ${ }^{10-13} \mathrm{Im}$ mune complexes were measured by the $\mathrm{Clq}$ binding assay of Zubler et al. (C1q polyethylene glycol

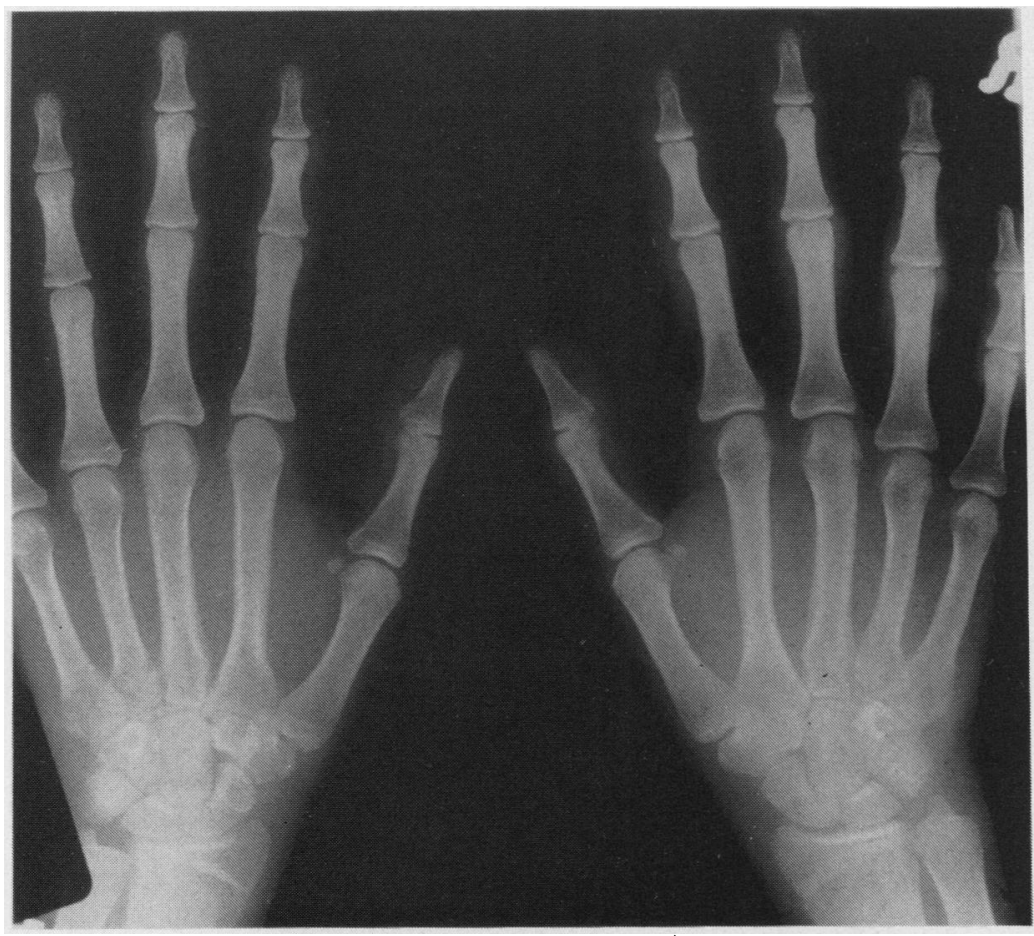

Fig. 1 Patient No 1 hand x-ray (March 1975). Soft tissue swelling is seen around several proximal and distal interphalangeal joints.

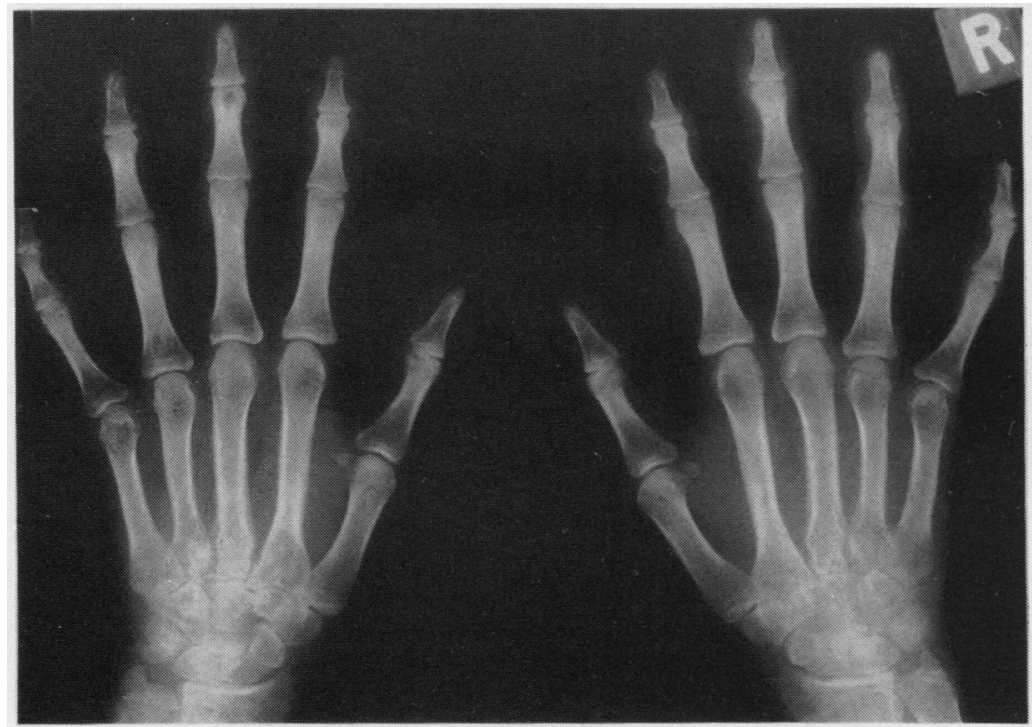

Fig. 2 (a) Patient No 1 hand $\mathrm{x}$-ray (March 1976). Soft tissue swelling is again seen around several proximal and distal interphalangeal joints.

Periarticular osteoporosis at the metacarpophalangeal joints, small erosions at several distal interphalangeal joints, and numerous carpal cysts are evident. (b) Close up of Fig. $2 a$ distal interphalangeal joint left middle finger to show small erosions. 


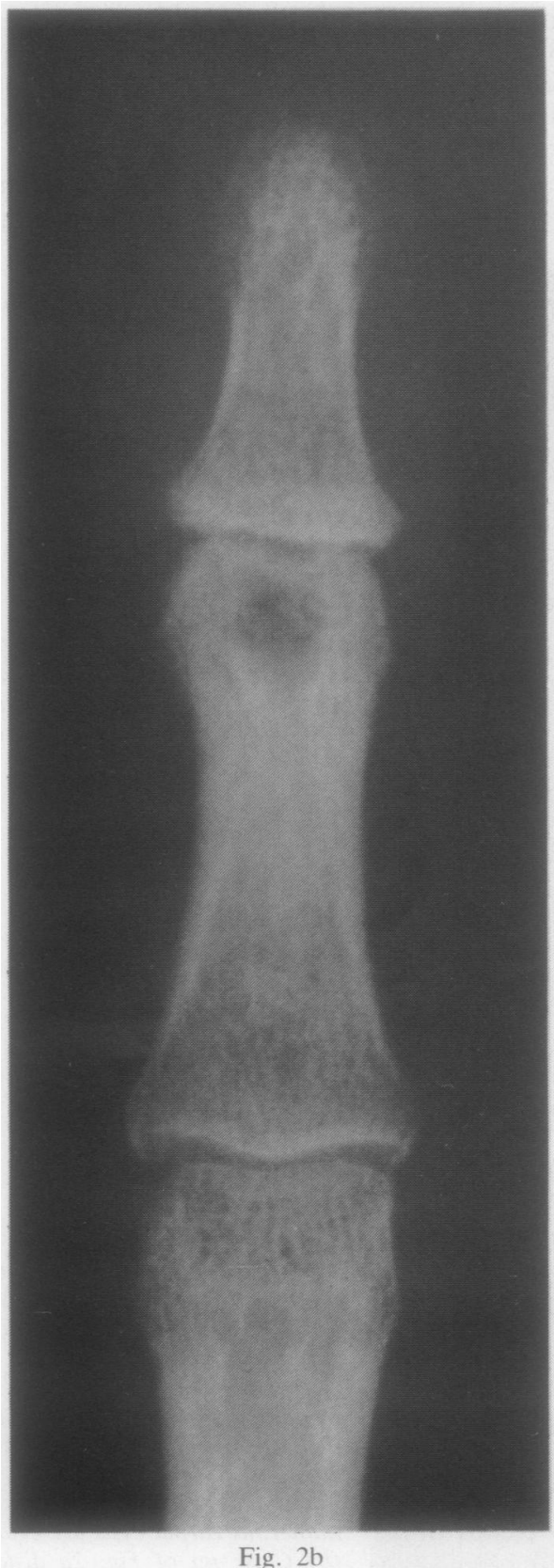

$(\mathrm{PEG}))^{14}$ and the C1q solid phase assay of Hay $\boldsymbol{e t}$ al. ${ }^{15}$ IgG- and IgA-containing complexes were identified by a solid phase (Fab) ${ }_{2}$ anti-C3 assay after binding of peroxidase-conjugated (Fab $)_{2}$ anti-IgG or $(\mathrm{Fab})_{2}$ anti-IgA (unpublished data). The significance was assessed by Fisher's exact probability test.

\section{Results}

CASE STUDY OF SIX PATIENTS WITH

COELIAC-RELATED ARTHRITIS (CRA)

Case history

An 18-year-old female student (patient No 1) $\frac{\bar{\sigma}}{\mathrm{c}}$ developed pain and swelling of both elbows and $\overrightarrow{\widetilde{\sigma}}$ ankles in July 1974. Symptoms partially subsided $\stackrel{\varrho}{\circ}$ over the following months but were accompanied by s an erythematous papular rash over face, forearms, $\vec{O}$ and legs. By March 1975 she was unwell with active $\overrightarrow{-}$ synovitis of several proximal and distal interpha- $\vec{\sigma}$ langeal joints, right wrist, and both knees. The ESR was $28 \mathrm{~mm} / \mathrm{h}$. The following investigations were? normal or negative: haemoglobin, white cell count, $\overrightarrow{+}$ rheumatoid arthritis latex test, antinuclear anti- -0 bodies, calcium, phosphate, and alkaline phospha-tase. Hand $x$-rays showed soft tissue swelling only (Fig. 1).

Her joint symptoms continued, accompanied by $\overrightarrow{c s}$ worsening morning stiffness, malaise, and weight loss, until March 1976 when further investigations $\overrightarrow{\mathbb{D}}$ revealed an ESR of $48 \mathrm{~mm} / \mathrm{h}$, haemoglobin $9.9 \mathrm{~g} / \mathrm{dl}$, mean corpuscular volume (MCV) $120 \mathrm{fl}$, and low serum iron and folate. Immunoglobulins wege $\vec{\circ}$ normal. $X$-rays of the hand showed periarticularroo osteoporosis and small erosions at the distal int phalangeal joints (Figs 2a and b). Barium followo through suggested malabsorption, and jejunal biopsy showed subtotal villous atrophy consistent with coeliac disease.

She was placed on a gluten-free diet and within $\cong$ one week noted improvement in her arthritis. By를 September 1976 her joint symptoms had resolved 3 completely and she had gained weight. The only? finding was residual swelling of the distal interphalangeal joints. She has remained well subsequently. Hand $x$-ray in 1983 showed healing of the erosions (Fig. 3).

Of the initial six patients (Table 1) four were female and two male. Age at diagnosis of coeliac 3 disease ranged from 20 to 60 years (mean 39.30 years).

Duration of symptoms (Table 1). Joint paino preceded diagnosis by up to three years in five patients and by 15 years in one patient. In threes cases there were no bowel symptoms, the diagnosis $N$ being suspected because of associated anaemia.

Pattern of joint involvement (Fig. 4). The distribu-O tion of arthritis varied widely. Lumbar spine, hip knee, and shoulder were affected most commonly. Pain at rest (six patients), morning stiffness of mores than 30 min (four patients), symptomatic flares (five patients), and joint swelling (two patients) wereo prominent symptoms. Painful limitation of move- $-\overrightarrow{\mathbb{D}}$ 


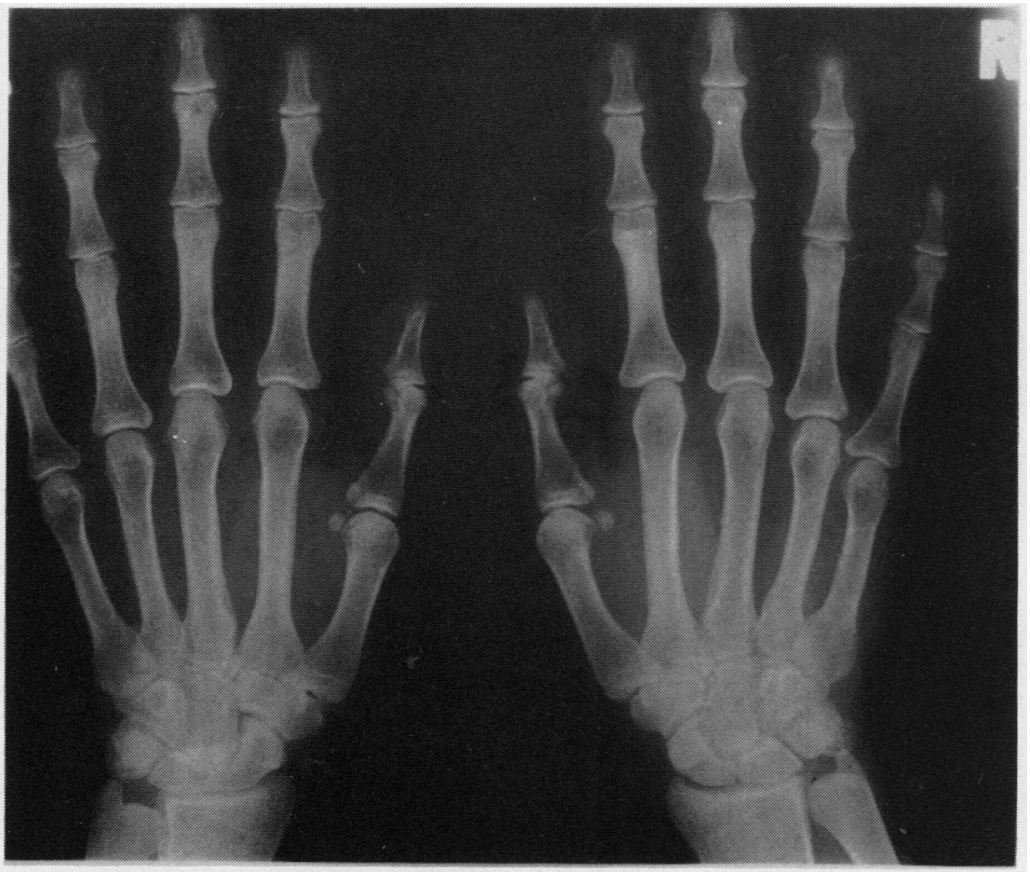

Fig. 3 Patient No 1 hand $\mathrm{x}$-ray (October 1983). Erosions at the distal interphalangeal joints have resolved.

ment (five patients) and joint tenderness (four patients) were the commonest physical signs.

Other prominent clinical features. Five patients complained of malaise and weight loss. Proximal myopathy was noted in two cases.

Laboratory data (Table 2). Useful screening tests included evidence of anaemia (five patients), macrocytosis (four patients), and low serum folate (all six patients). ESR was clearly raised in two patients and marginally raised in a further three patients. Biochemical evidence for coexisting osteomalacia was found in three patients (Nos 2, 4, and 6). All were latex negative and had normal immunoglobulins.

$X$-ray changes. $X$-rays were normal in four patients. One patient showed congenital fusion of
Lumbar spine

Hip

Knee

Shoulder

Elbow

Wrist

Ankle

Cervical spine

Sacroiliac joint

Proximal I $P$ joint

Distal I P joint

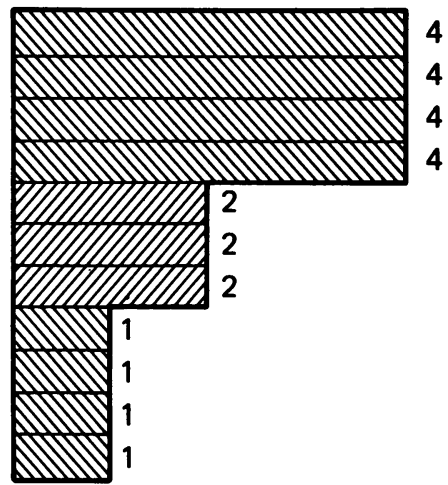

Fig. 4 Pattern of joint involvement in six patients with coeliac-related arthritis. (IP joint=interphalangeal joint.)

Table 1 Six patients with coeliac-related arthritis $(C R A)$ : presentation

\begin{tabular}{lllll}
\hline Patient & Sex & $\begin{array}{l}\text { Age at diagnosis } \\
\text { of coeliac disease }\end{array}$ & $\begin{array}{l}\text { Duration of bowel symptoms } \\
\text { (years) }\end{array}$ & $\begin{array}{l}\text { Duration of joint symptoms } \\
\text { (years) }\end{array}$ \\
\hline 1 & F & 20 & - & 2 \\
2 & F & 49 & $0 \cdot 5$ & 3 \\
3 & M & 60 & - & $1 \cdot 3$ \\
4 & M & 47 & $2 \cdot 5$ & 3 \\
5 & F & 20 & - & $15+$ \\
6 & F & 40 & $15+$ & 15 \\
\hline
\end{tabular}


Table 2 Six patients with CRA: laboratory data

\begin{tabular}{|c|c|c|c|c|c|c|c|}
\hline Patient & Haemoglobin & $M C V$ & Serum folate & $\begin{array}{l}E S R \\
(\mathrm{~mm} / \mathrm{h})\end{array}$ & $\begin{array}{l}\text { Calcium } \\
(\text { mmolll })\end{array}$ & $\begin{array}{l}\text { Phosphate } \\
\text { (mmolll) }\end{array}$ & $\begin{array}{l}\text { Alkaline } \\
\text { phosphatase* }\end{array}$ \\
\hline 1 & $\downarrow$ & $\uparrow$ & $\downarrow$ & 54 & $2 \cdot 30$ & $1 \cdot 26$ & 122 \\
\hline 2 & $\downarrow$ & $\uparrow$ & $\downarrow$ & 26 & $2 \cdot 37$ & 0.84 & 604 \\
\hline 3 & $\mathbf{N}$ & $\uparrow$ & $\downarrow$ & 17 & $2 \cdot 40$ & $1 \cdot 13$ & 64 \\
\hline 4 & $\downarrow$ & $\mathbf{N}$ & $\downarrow$ & 22 & 1.68 & 0.91 & 264 \\
\hline 5 & $\downarrow$ & $\mathbf{N}$ & $\downarrow$ & 80 & $2 \cdot 28$ & $1 \cdot 16$ & 105 \\
\hline 6 & $\downarrow$ & $\uparrow$ & $\downarrow$ & 7 & $1 \cdot 70$ & 1.23 & 24 \\
\hline
\end{tabular}

* = Normal range $=50-150 \mathrm{IU} / \mathrm{l}$.

$\mathbf{N}=$ normal; $\downarrow=$ low; $\uparrow=$ raised.

cervical vertebra $\mathrm{C} 2$ and $\mathrm{C} 3$ and asymptomatic sacroiliitis. The $x$-ray findings of patient No 1 have been presented above.

Tissue type (Table 3). HLA-type A1, B8, DR3 was present in five patients. HLA-B27 was found in two patients, neither of whom had clinical evidence of ankylosing spondylitis. $X$-ray evidence of sacroiliitis (asymptomatic) was present in one of these.

Outcome. All patients were placed on a glutenfree diet after demonstration of coeliac disease by jejunal biopsy. Three patients experienced complete and lasting remission of their arthritis within three months. Two patients noted marked improvement over a similar time period but continue to experience residual joint symptoms. A further patient noted moderate improvement only.

Gluten challenge. Three patients agreed to undergo gluten challenge for the purposes of: $(a)$ confirming the diagnosis of coeliac disease; and $(b)$ observing the effect of a normal diet on the course of their arthritis. Each patient received a normal diet plus $20 \mathrm{~g}$ additional gluten per day. Jejunal biopsies after three weeks in patients No 1 and 5 and after one week in patient No 3 all showed relapse, confirming the diagnosis of coeliac disease. No patient experienced a return of joint symptoms over this period. A fourth patient (No 4) reported exacerbation of pain and swelling in his left knee 24 hours after lapsing from his gluten-free diet, though this episode was not witnessed by us.

Table 3 Tissue type of six patients with CRA

\begin{tabular}{lllll}
\hline Patient & $A$ & $B$ & $C$ & $D R$ \\
\hline 1 & 1,2 & $8, \mathbf{w} 44$ & w7,- & 2,3 \\
2 & $1,-$ & $8,-$ & w7,- & $3,-$ \\
3 & 1,11 & 8,27 & w2,w7 & 3,4 \\
4 & 1,3 & $8, \mathbf{w} 51$ & w7,- & 3,7 \\
5 & 2, w32 & w44,w50 & ND & ND \\
6 & 1,2 & 8,27 & w1,w7 & 3,7 \\
\hline
\end{tabular}

ND=not done.
Immune complex and antibody studies. Immune complexes were detected in four of the six patients but no overall pattern emerged. Representative data from patient No 5 are illustrated in Fig. 5. IgA containing complexes were not found in any patient $\circ$ Immune complexes detected by the remaining methods showed great variability on repeated sam-s pling both before and after treatment. No significant rise in levels was seen during the period of glutend challenge. Antigliadin and antireticulin antibodies tended to be high in untreated patients falling to normal with institution of a gluten-free diet ag 40 rising again during gluten challenge. Antiovalbun inn antibodies (reflecting immune response to noi specific dietary proteins) were detected in threo patients both before and repeatedly after institution of a gluten-free diet.

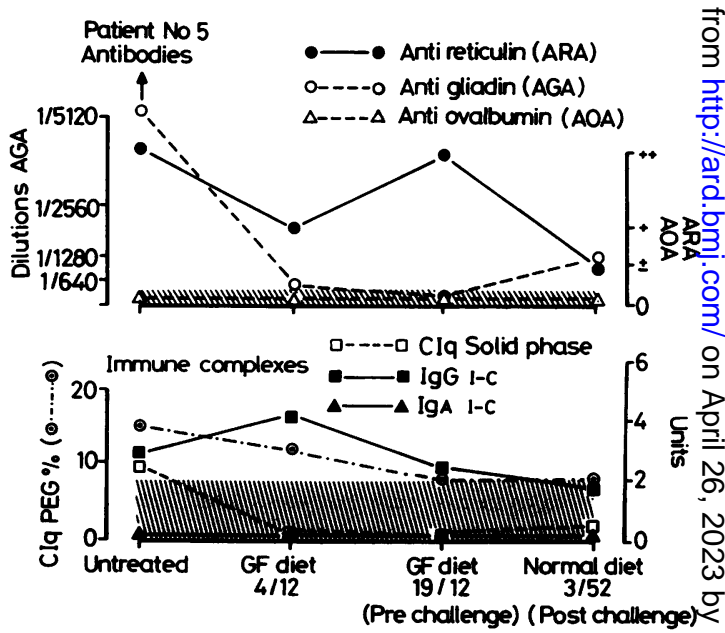

Fig. 5 Antigliadin $(A G A)$, antireticulin (ARA), antiovalbumin (AOA) antibodies and immune complexe detected by four methods (see text) in patient No 5 before treatment, after 4 months and 19 months on a gluten-free $(G F)$ diet, and after a three-week gluten challenge. The hatched area indicates the normal ranges. 
SEARCH FOR ARTHRITIS IN A TREATED

COELIAC POPULATION

The age range of the 160 treated coeliac patients examined was 15 to 81 years (mean 46.5 years), female to male ratio $3 \cdot 3: 1$, and time from diagnosis one month to 67 years (mean 11.4 years). The distribution of locomotor disease is shown in Table 4. Evidence of synovitis for which no clear diagnosis could be made ('undifferentiated arthritis', Table 4) was found in six patients. The small joints of the hands and wrists were affected most commonly and symptoms in all subjects settled within three years of onset. This arthritis was not thought to be attributable to coeliac disease. No specific arthritis was identified and there was no evidence of ankylosing spondylitis.

The age range of the 100 patients with Crohn's disease examined was similar: 16 to 82 years (mean 38.3 years), female to male ratio $2: 1$, and time from diagnosis five months to 35 years (mean $9 \cdot 1$ years). The distribution of locomotor symptoms is shown in Table 5. Seronegative polyarthritis was found in $23 \%$ and ankylosing spondylitis in $5 \%(p<0.01)$.

\section{Discussion}

Well recognised musculoskeletal manifestations of coeliac disease (CD) include metabolic bone dis-

Table 4 Pattern of locomotor disease in 160 patients with treated coeliac disease

\begin{tabular}{lr}
\hline Osteoarthritis, cervical/lumbar spondylosis & 20 \\
Musculoskeletal pain without signs & 14 \\
Undifferentiated arthritis & 6 \\
Right MCPJs, neck, shoulders & \\
Right +left wrists & \\
Right +left PIPJs and MCPJs & \\
IPJ right thumb & \\
Right +left PIPJs & 3 \\
Right wrist and knee & 1 \\
Osteomalacia & 1 \\
Hypermobility & \\
Gout &
\end{tabular}

PIPJ=proximal interphalangeal joint; $\mathrm{MCPJ}=$ metacarpophalangeal joint.

Table 5 Pattern of locomotor disease in 100 patients with Crohn's disease

Seronegative polyarthritis

Osteoarthritis, cervical/umbar spondylosis 15

Musculoskeletal pain without signs

Ankylosing spondylitis

Symptomatic sacroiliitis without $x$-ray signs

Polymyalgia rheumatica

Gout

Palindromic rheumatism

Hypermobility ease, muscle weakness (e.g., due to hypokalaemia) and paraesthesiae (due to hypocalcaemia). ${ }^{5}$ In addition there have been isolated reports of polymyositis, ${ }^{16}$ pericarditis, ${ }^{17}$ and cutaneous vasculitis, ${ }^{18}$ which resolved with institution of a gluten-free diet. Adelizzi et al. first reported arthritis as a presenting symptom of $\mathrm{CD} .{ }^{6}$ Their patient, a 28-year-old white male, developed an acute asymmetrical arthritis involving knee, ankle, and subtalar joints. $\mathrm{CD}$ was confirmed by jejunal biopsy. No other cause of arthritis was found, and permanent resolution occurred with institution of a gluten-free diet. Subsequently a group of French workers ${ }^{19}$ have reported two patients with seronegative polyarthritis in whom CD was diagnosed and whose arthritis resolved completely on a gluten-free diet.

We have identified a further six patients with CD in whom arthritis was prominent at diagnosis. The causal relationship of $\mathrm{CD}$ and arthritis is supported by the absence of other disease and by the striking response to a gluten-free diet. Only two gastrointestinal conditions associated with a flat jejunal biopsy may cause arthritis - hypogammaglobulinaemia and lymphoma. Immunoglobulin levels and follow up over a minimum of four years have excluded these. Similarly no evidence of Crohn's disease, Whipple's disease, or causes of reactive arthritis were found. Osteomalacia was thought to contribute to (but not adequately to account for) symptoms in three patients.

The very varied pattern of arthritis in these patients makes identification of $\mathrm{CD}$ difficult, particularly since $50 \%$ of them had no bowel symptoms. Malaise and weight loss were useful clinical pointers and low serum folate was found in all six patients. The value of this test in tracing occult adult $C D$ has recently been emphasised. ${ }^{20}$

The pathogenesis of the arthritis is unclear, as indeed is the pathogenesis of $C D$ itself. Current evidence favours immunologically mediated mucosal injury in the context of marked genetic susceptibility. The high frequency of HLA-B8,-DR3 has been repeatedly reported. ${ }^{521}$ It is possible that the arthropathy may be due to absorption through damaged jejunal mucosal of either immune complexes directly or gut-derived antigens which provoke a humoral or cell-mediated response resulting in joint injury. Intestinal permeability is known to be abnormal in untreated coeliac disease ${ }^{4}$ returning to normal within six months of the institution of a gluten-free diet. In keeping with the findings of other workers, ${ }^{22} 23$ we have shown the presence of circulating immune complexes in the majority of our patients, but the levels do not correlate well with the onset of arthritis. The failure to provoke arthritis after gluten challenge despite relapse of jejunal 
mucosa suggests that gluten or its constituents are not directly responsible for promoting arthritis. We have not excluded this possibility, however, since the bowel may relapse more quickly than the joints. It was considered unethical to extend the period of gluten challenge beyond three weeks.

We postulate that abnormal mucosal permeability in untreated coeliac disease allows access to as yet unidentified provoking antigens which may vary widely between individuals. This would account for the varied clinical picture and the absence of coeliac-related arthritis in the treated population. We have not investigated the incidence of arthritis amongst untreated coeliacs. The lengthy time period over which our six patients were identified suggests that the incidence amongst this population is very low. This implies that altered intestinal permeability is only one of several factors leading to arthritis. A better understanding of the mechanism of this rare form of arthritis may provide important clues to the wider role of gastrointestinal antigens and genetic susceptibility in rheumatic disease.

\section{References}

1 Smith R. The surgical relief of intestinal foci of infection in arthritis deformans. Ann Surg 1922; 76: 515-8.

2 Wright $\mathrm{V}$, Watkinson $\mathrm{G}$. The arthritis of ulcerative colitis. Medicine (Baltimore) 1959; 38: 243-59.

3 Neumann V, Wright V. Arthritis associated with bowel disease. Clin Gastroenterol 1983; 12: 767-95.

4 Hamilton I, Cobden I, Rothwell J, Axon A T R. Intestinal permeability in coeliac disease: the response to gluten withdrawal and single-dose gluten challenge. Gut 1982; 23: 202-10.

5 Falchuk Z M. Gluten-sensitive enteropathy. Clin Gastroenterol 1983: 12: 475-93.

6 Adelizzi R A, Pecora A A, Chiesa J C. Celiac disease: case report with an associated arthropathy. Am J Gastroenterol 1982; 77: 481-5.

7 Bennet P H, Burch T A. In: Bennet P H, Wood P H N, eds. Population studies of the rheumatic diseases. Amsterdam: Exerpta Medica, 1968: 305.

8 Festenstein H, Adams E, Burke J, Oliver R T D, Sachs J A, Wolf $E$. The distribution of HL-A antigens in expatriates from East Bengal living in London. 5th international symposium of the histocompatibility workshop. In: Histocompatibility testing Copenhagen: Munksgaard, 1972: 175-8.

9 Van Rood J J, van Leeuwen A, Ploem J S. Simultaneous detection of two cell population by two-colour fluorescence an $\overline{\widehat{S}}$ application to the recognition of B cell determinants. Naturg 1976; 262: 795-7.

10 Unsworth D J, Leonard J N, McMinn R M H, Swain A F Holborow E J, Fry L. Antigliadin antibodies and smaff intestinal mucosal damage in dermatitis herpetiformis. $\mathrm{Br} \Phi$ Dermatol 1981; 105: 653-8.

11 Unsworth D J, Manuel P D, Walker-Smith J A, Campbell C A Johnson G D, Holborow E J. A new immunofluorescent bloo test for gluten sensitivity. Arch Dis Child 1981; 56: 864-8:-

12 Seah P P, Fry L, Hoffbrand A V, Holborow E J. Tissue autoantibodies in dermatitis herpetiformis and adult coelia disease. Lancet 1971; i: 834-6.

13 Kendrick R G, Walker-Smith J A. Immunoglobulins an dietary protein antibodies in childhood coeliac disease. Gü 1970; 11: 635-40.

14 Zubler R H, Lange G, Lambert P H, Miescher P A. DetectiofP of immune complexes in unheated sera by a modified ${ }^{125} \mathrm{ke}$ $\mathrm{Clq}$ binding test. Effect of heating on the binding of C1q blu immune complexes and application of the test to systemic lupus erythematosus. J Immunol 1976; 116: 232-5.

15 Hay F C, Nineham L J, Roitt I M. Routine assay for the detection of immune complexes of known immunoglobulim class using solid phase Clq. Clin Exp Immunol 1976; 2क्ष 396-400.

16 Henriksson K G, Hallert C, Norrby K, Walan A. Polymyositis and adult coeliac disease. Acta Neurol Scand 1982; 65: 301-19믐

17 Dawes P T, Atherton S T. Coeliac disease presentings as recurrent pericarditis. Lancet 1981; i: 1021-2.

18 Meyers S, Dikman S, Spiera H, Schultz N, Janowitz Cutaneous vasculitis complicating coeliac disease. Gut 198k 61-4.

19 Prier A, Le Quintrec Y, Camus J P, Gendre J P, Pradel BS Polyarthrites inflammatoires associées a une atrophie villos taire du grêle. Rev Rhum Mal Osteoartic 1980; 47: 661-5. Џ

20 Hallert C, Tobiasson P, Walan A. Serum folate determination in tracing adult coeliacs. Scand J Gastroenterol 1981; 16: 263-7P.

21 Scott H, Brandtzaeg P, Thorsby E, Baklein K, Fausa O, Ek $\overrightarrow{\vec{F}}$ Mucosal and systemic immune response patterns in coelia@ disease. Ann Allergy 1983; 51: 233-9.

22 Doe W F, Booth C C, Brown D L. Evidence for complement binding immune complexes in adult coeliac disease, Crohn's. disease and ulcerative colitis. Lancet 1973; i: 402-3.

23 Mohammed I, Holborow E J, Fry L, Thompson B Rō Hoffbrand A V, Steward J S. Multiple immune complexes and hypocomplementaemia in dermatitis herpetiformis and coelia disease. Lancet 1976; ii: 487-90. 